\title{
DESENVOL VIMENTO DE APLICATIVO PARA REALIZAÇÃO DE PRÁTICAS PROFISSIONAIS À LUZ DA METODOLOGIA SENAI DE EDUCAÇÃO PROFISSIONAL
}

\author{
DEVELOPMENT OF APPLICATION FOR THE REALIZATION OF \\ PROFESSIONAL PRACTICES IN THE LIGHT OF THE SENAI METHODOLOGY \\ OF PROFESSIONAL EDUCATION
}

\author{
Filipe Soares Martins \\ SENAI - Serviço Nacional de Aprendizagem Industrial \\ filipe.s.martins@gmail.com
}

\begin{abstract}
RESUMO
Este artigo explica o desenvolvimento e a aplicação de uma ferramenta informatizada e de uso livre para criação de trajetos otimizados a ser utilizada durante as aulas práticas de um componente curricular do curso técnico em logística em uma das escolas da rede SENAI-ES. Como procedimento metodológico foram utilizadas as pesquisas aplicada e de laboratório. Foi desenvolvido um sistema baseado em linguagem VBA, integrado ao Microsoft Excel utilizando o suplemento OpenSolver para execução dos cálculos de definição do melhor trajeto a partir de uma situação problema definida à luz da metodologia SENAI de educação profissional. O estudo concluiu que a utilização da ferramenta permitiu atingir o objetivo central de permitir ao instrutor aplicar uma situação de aprendizagem de acordo com a metodologia educacional proposta e possibilitou ao discente alinhar os conceitos teóricos à prática profissional e apoiá-lo no processo de tomada de decisão quanto a qual trajeto deve ser selecionado.
\end{abstract}

Palavras chave: Distribuição. Otimização. Práticas Educacionais

\begin{abstract}
This article explains the development and application of a computerized and free use tool to create optimized paths to be used during the practical classes of a curricular component of the technical course in logistics in one of the schools of the SENAI-ES network. As a methodological procedure, applied and laboratory research were used. A system based on VBA language was developed, integrated to Microsoft Excel using the OpenSolver supplement to perform the calculations of definition of the best path from a problem situation defined in the light of SENAI methodology of professional education. The study concluded that the use of the tool allowed to achieve the central objective of allowing the instructor to apply a learning situation according to the proposed educational methodology and enabled the student to align the theoretical concepts with the professional practice and to support it in the decision making process which path to select.
\end{abstract}

Keywords: Distribution. Optimization. Educational Practices

\section{INTRODUÇÃO}

O Ministério da Educação e da Cultura (MEC) por meio da Secretaria de Educação Profissional e Tecnológica (SETEC) coordena toda a política de educação profissionalizante do país. Desta maneira zela pelas instituições que compõe a Rede Federal de Educação Profissional, Científica e Tecnológica. Esta Rede Federal é composta por Institutos Federais, Centros Federais de Educação, Escolas Técnicas vinculadas as universidades federais. Além da Rede Federal, com a publicação da lei 12.513 de 26 de outubro de 2011, os Serviços Nacionais de Aprendizagem passaram a 
integrar o Sistema Federal de Ensino, tornando-os capazes de criar instituições de educação profissional de nível técnico na condição de mantenedores, ou seja, transformando-os em instituições autônomas no que diz respeito a criação de cursos, a partir da observação das leis que regem este tipo de operação.

Tal autorização demonstra a importância e a necessidade de formar alunos capazes de enxergar respostas para os diversos problemas enfrentados pelas organizações no dia a dia. Desta forma, uma das maneiras de promover a qualificação dos estudantes é proporcionar aulas práticas onde são propostas situações problema em que são simuladas circunstâncias reais do dia a dia de um profissional que atua na área escolhida pelo estudante. Nesta perspectiva de aulas práticas, o Serviço Nacional de Aprendizagem Industrial (SENAI) é pioneiro na qualificação de mão de obra desde a iniciação profissional, passando pelos cursos técnicos até a qualificação avançada, como a presente nos programas de mestrado e doutorado ofertados pelo SENAI, utilizando a prática em aula como norteadora do processo de ensino-aprendizagem.

Este artigo apresenta o desenvolvimento de um aplicativo que auxiliará o curso técnico em logística do SENAI - ES a simular de maneira confiável o processo de roteirização baseado na abordagem proposta no problema do caixeiro viajante (PCV).

Desta maneira, o objetivo deste artigo foi descrever o desenvolvimento de um software de apoio à tomada de decisão na seleção de trajetos durante as aulas práticas da disciplina de gestão da distribuição do curso técnico em logística do SENAI - ES a partir da utilização de ferramentas de gestão tradicionais como Microsoft Excel, a ferramenta Visual Basic For Applications (VBA), o suplemento OpenSolver e consultas a base de dados online do Google Maps por meio da internet. Assim sendo, o desenvolvimento deste software se justifica na necessidade da instituição e dos instrutores possuírem a disposição um software livre para ser ajustado e utilizado de acordo com as demandas do curso técnico em logística e com distribuição gratuita.

Esta pesquisa foi classificada de acordo com a proposta de Vergara (1990) que a qualifica de duas maneiras: quanto aos fins e quanto aos meios. Quanto aos fins é uma pesquisa aplicada por ser motivada pela necessidade real da resolução de um problema concreto e imediato. Neste caso, a necessidade de um software que permita a simulação e elaboração de caminhos otimizados. Quanto aos meios trata-se de pesquisa de laboratório face às simulações executadas no laboratório de informática da instituição.

A utilização de softwares para apoio às atividades escolares é uma realidade constante no ambiente acadêmico. É possível ver a variedade das aplicações nos estudos de Santos (2016) que propõe a utilização de simuladores para a aprendizagem de redes de computadores. Além deste, Rovani et al. (2012) recomendam o uso de simuladores para o ensino de geografia. Já Heckler, Saraiva e Filho (2007) falam sobre o uso de simuladores para o ensino da disciplina de física. Ainda é possível citar o estudo feito por Barros, Cazella et al. (2012) que apresentam o uso de um simulador de casos clínicos complexos no ensino de componentes curriculares do curso de medicina. Aplicado a problemas de distribuição Senna e Gomes et al. (2015) demonstram o uso do VBA para o desenvolvimento de uma ferramenta para o ensino do algoritmo de Dijkstra. 
O software foi idealizado para ser utilizado durante as aulas de gestão da distribuição do curso técnico em logística do SENAI - ES, sendo que as aulas ocorrem na unidade operacional instalada no município de Vila Velha tendo como ambiente pedagógico a interação entre sala de aula convencional, laboratório de movimentação e armazenagem de materiais e o laboratório de informática.

\subsection{Educação Profissional e Tecnológica no Brasil}

Em seu princípio, as iniciativas de educação profissional no Brasil partiam de associações civis religiosas, filantrópicas ou de esferas estatais. As forças armadas, marinha e exército, tiveram papel fundamental na preparação dos discentes nos ofícios voltados à manufatura (MANFREDI, 2002).

Além das forças armadas, Manfredi (2002) destaca as Casas de Educandos Artífices que adotaram o modelo de aprendizagem vigentes no âmbito militar, incluindo os padrões de hierarquia e disciplina. Estas casas eram mantidas por sociedades particulares com auxílio governamental e o perfil discente formado por órfãos, abandonados e desvalidos. Nestas casas, os alunos recebiam instrução primária e aprendiam ofícios como tipografia, alfaiataria, tornearia, carpintaria e sapataria.

Manfredi (2002, p. 77) também evidencia os Liceus de Artes e Ofícios "que também nasceram da iniciativa de entidades da sociedade civil cujo recursos vinham de cotas de sócios ou de doação de benfeitores". De modo geral, o acesso aos cursos era livre, exceto para os escravos. Durante o período republicano, os liceus foram mantidos e em alguns casos ampliados, servindo assim de base para a construção de uma rede nacional de escolas voltadas a educação profissional (MANFREDI, 2002).

Nos Liceus de Artes e Ofícios as matérias que constituíam os cursos eram basicamente divididas em dois grupos: ciências aplicadas e artes. No caso das ciências aplicadas disciplinas voltadas ao estudo da aritmética, álgebra, geometria, física, química e mecânica, enquanto no grupo de artes disciplinas voltadas a desenho geométrico, humano, mecânico, ornamental e arquitetura civil (MANFREDI, 2002)."No Brasil, a implantação de métodos baseados nos princípios da organização racional do trabalho ocorreu, sem dúvida, nesses cursos do Liceu de Artes e Ofícios” (SENAI, 2012, p. 114).

No Brasil, durante a década de 90, foi instituída a Lei de Diretrizes e Bases da Educação (Lei 9.394/96) e o Decreto Federal 2.208/97 que instituíram as bases para a reforma do ensino profissionalizante. No referido decreto afirma-se como objetivo da educação profissional a formação de técnicos para diferentes setores da economia, especialização e aperfeiçoamento dos conhecimentos tecnológicos e a qualificação, requalificação e treinamento de jovens e adultos com qualquer nível de escolaridade visando sua inserção no mercado de trabalho (MANFREDI, 2002).

O Sistema S, como uma rede de educação profissional e integrante do Sistema Federal de Ensino é formado por: SENAI (Serviço Nacional de Aprendizagem Industrial), voltado a atender o setor industrial; SENAC (Serviço Nacional de Aprendizagem Comercial), para atender o setor de comércios e serviços; SENAR (Serviço Nacional de Aprendizagem Rural) voltado ao setor agrícola; SENAT (Serviço Nacional de Aprendizagem de Transportes) para o setor de transportes e SEBRAE (Serviço de Apoio à Pequena e Média Empresa). Este sistema tem papel importante no desenvolvimento da educação profissional no Brasil. 
O SENAI foi criado pelo Decreto-Lei 4.048, de 22 de janeiro de 1942 em virtude da necessidade de expansão da indústria nacional face a política econômica vigente na época denominada pelos economistas como modelo de substituição de importações, que forçou a indústria nacional a se atualizar tanto em projetos quanto em força de trabalho para atender a demanda existente, principalmente à criada pela $2^{\text {a }}$ Guerra Mundial (SENAI S. N., 2012). Desde sua criação, o SENAI representa a maior rede de educação profissional formadora de força de trabalho para os diferentes setores empresariais e ao longo de sua trajetória, busca se adequar as exigências do mercado e as transformações políticas e econômicas (MANFREDI, 2002).

No sentido de tornar a educação profissional atrativa, as tecnologias da informação e comunicação são meios de melhorar o acesso, a eficiência e a qualidade da educação profissional, sendo de fato, um meio para apoiar alunos, instrutores na vivência de uma era da informação (SENAI, 2015). Neste caminho, ao aluno é permitido acesso a vários tipos de tecnologias a medida que as oportunidades aparecem, podendo ser destacadas a utilização de livros digitais, softwares específicos, simuladores digitais dentre outros.

Assim sendo, por meio de sua metodologia de educação, o SENAI incentiva a prática docente baseada em situações de aprendizagem que colocam o aluno no centro do processo educacional, de forma que o instrutor seja um mediador entre o conhecimento e o aluno. Nesta prática, há o desenvolvimento de capacidades por meio da contextualização, utilizando situações-problema, estudos de caso, projetos ou pesquisas aplicadas, demonstrando proximidade entre o que é aprendido na escola e o que é aplicado no mercado de trabalho, dando assim um significado muito forte a aprendizagem (SENAI, 2013).

\subsection{Distribuição Logística, Simulação e Métodos Para Roteirização}

A distribuição faz parte dos processos logísticos podendo ser conceituada como "processos operacionais e de controle que permitem transferir os produtos desde o ponto de fabricação até o ponto em que a mercadoria é finamente entregue ao consumidor" (NOVAES, 2007, p. 123). Assim, os responsáveis pela distribuição operam elementos específicos como depósitos, estoques, equipamentos de carga e descarga e veículos (NOVAES, 2007).

Segundo Bateman et al. (2013, p.1) "simulação é a experimentação de um sistema real através de modelos". Bateman et al. (2013, p. 2) ainda complementam dizendo que a simulação é "um processo de experimentação como um modelo detalhado de um sistema real para determinar como o sistema responderá a mudanças em sua estrutura, ambiente ou condições de retorno". Neste sentido, simular um processo permite analisar a representatividade de um modelo de simulação assim como prever com certo grau de precisão os resultados de um processo simulado. "Modelos de simulação aparecem sob a forma de jogos de empresa, simuladores de voos, modelos físicos de aeronaves para testes em túnel de vento etc". (DA SILVA, DA SILVA, et al., 1998)

Segundo Arenales, Armentano, Morabito e Yanasse (2015, p. 260) "os problemas de roteamento envolvem o projeto de rotas de entrega e/ou coleta de custo mínimo, partido de um ou mais depósitos para um número de clientes, sujeito a restrições adicionais". Analisando a cadeia de suprimentos, nota-se a importância da aplicação da roteirização no gerenciamento da distribuição e logística. Colocando-se no lugar do gestor que 
precisa fazer a programação do percurso de veículos de uma frota é possível perceber a complexidade do problema à medida que são adicionados novos pontos de parada.

Diversos são os métodos para a roteirização de veículos. Um deles baseado no algoritmo de Dijkstra que encontra o menor caminho entre quaisquer dois nós de uma rede utilizando um procedimento iterativo, determinando em cada iteração o nó mais próximo do nó 1 , até que o nó $n$ seja atingido. (ARENALES, ARMENTANO, et al., 2015).

É possível citar o método de varredura que segundo Novaes (2007) é um método fácil de ser utilizado e de computação rápida. Ballou (2006) reforça a afirmação de Novaes dizendo que este método pode ser calculado a mão, mesmo em caso de grandes problemas de roteirização. Belfiore e Fávero (2012) descrevem o problema do caminho mais curto, também conhecido como problema do caminho mínimo como um método que busca encontrar o menor caminho entre dois nós de uma rede, podendo também ser aplicado para minimizar os custos totais de uma viagem ou o tempo da mesma. (BELFIORE e FÁVERO, 2012).

Por fim, o problema do caixeiro viajante (PCV), que consiste em determinar um único roteiro com o menor itinerário possível e que permita ao veículo visitar todos os nós de uma rede de distribuição uma única vez. Apesar de sua declaração ser simples, sua resolução é complexa e se torna cada vez mais complexa a medida que são incluídos no roteiro novos pontos de parada (NOVAES, 2007). Arenales, Armentano, Morabito e Yanasse (2015, p.250) afirmam que o problema do caixeiro viajante "é um dos problemas combinatórios mais conhecidos e pesquisados devido à sua aplicação em diversas áreas, tais como manufatura de circuitos, programação da produção, telecomunicações e sequenciamento de DNA". Belfiore e Fávaro (2012, p.301) apontam a seguinte modelagem para o PCV:

Variáveis de decisão:

$$
X_{i j}=\left\{\begin{array}{l}
1, \text { se o caixeiro viajante vai diretamente da cidade } i \text { para a cidade } j, i \neq j \\
0, \text { caso contrário }
\end{array}\right.
$$

Função objetivo:

$$
\min \mathrm{z} \sum_{i=1}^{n} \sum_{j=1}^{n} C_{i j} X_{i j}
$$

Sujeito a:

$$
\begin{aligned}
& \sum_{i=1}^{n} X_{i j}=1 \quad \forall_{j} \in N \\
& \sum_{j=1}^{n} X_{i j}=1 \quad \forall_{i} \in N \\
& \sum_{i, j \in S}^{n} X_{i j} \leq|S|-1 \quad \forall S \subset N \\
& X_{i j} \in\{0,1\} \forall_{i j} \in N
\end{aligned}
$$


A função objetivo buscar minimizar o custo ou a distância a ser percorrida. As restrições $1 \mathrm{e}$ 2 determinam que cada nó só poderá ser visitado uma vez. A restrição 3 impede que haja formação de sub-rotas. A restrição 4 determina que as variáveis de decisão sejam binárias (BELFIORE e FÁVERO, 2012).

\subsection{Desenvolvimento de aplicativos}

Visual Basic for Applications (VBA) é uma linguagem de programação que atua em conjunto com a suíte de aplicativos de escritório, Microsoft Office (DREUX e AZEVEDO, 2009). De maneira geral, o VBA é uma linguagem calcada no desenvolvimento de macros, ou seja, um conjunto de instruções formuladas para eliminar trabalhos repetitivos e que disponibiliza ao usuário a possibilidade de criar formulários para interação com o usuário de maneira simples. Como foi dito, dependendo do problema de roteirização, a resolução pode se tornar cada vez mais complexa. Para auxílio à resolução de problemas o Microsoft Excel dispõe de um suplemento nativo, chamado solver, que necessita de licença para desbloquear todas as suas funções (FRONTLINE SYSTEMS, 2018).

Semelhante ao solver nativo, o OpenSolver é um suplemento feito para ser utilizado no Microsoft Excel e dispõe de código aberto sob licença GPL (General Public License). Assim como o solver nativo, o OpenSolver permite ao usuário manipular manualmente as informações do problema a ser resolvido por meio da planilha tradicional e por meio de código de programação VBA, possibilitando assim a automação de diversas tarefas por meio das macros. (MASON, 2012)

\section{FERRAMENTA PROPOSTA}

Para desenvolver o sistema foi necessário concatenar os conhecimentos de processos de distribuição logística, pesquisa operacional e de programação de computadores. Com isso em mente foram definidas todas as etapas ou sequências de atividades que o sistema trabalharia. A figura 1 demonstra o funcionamento do sistema.

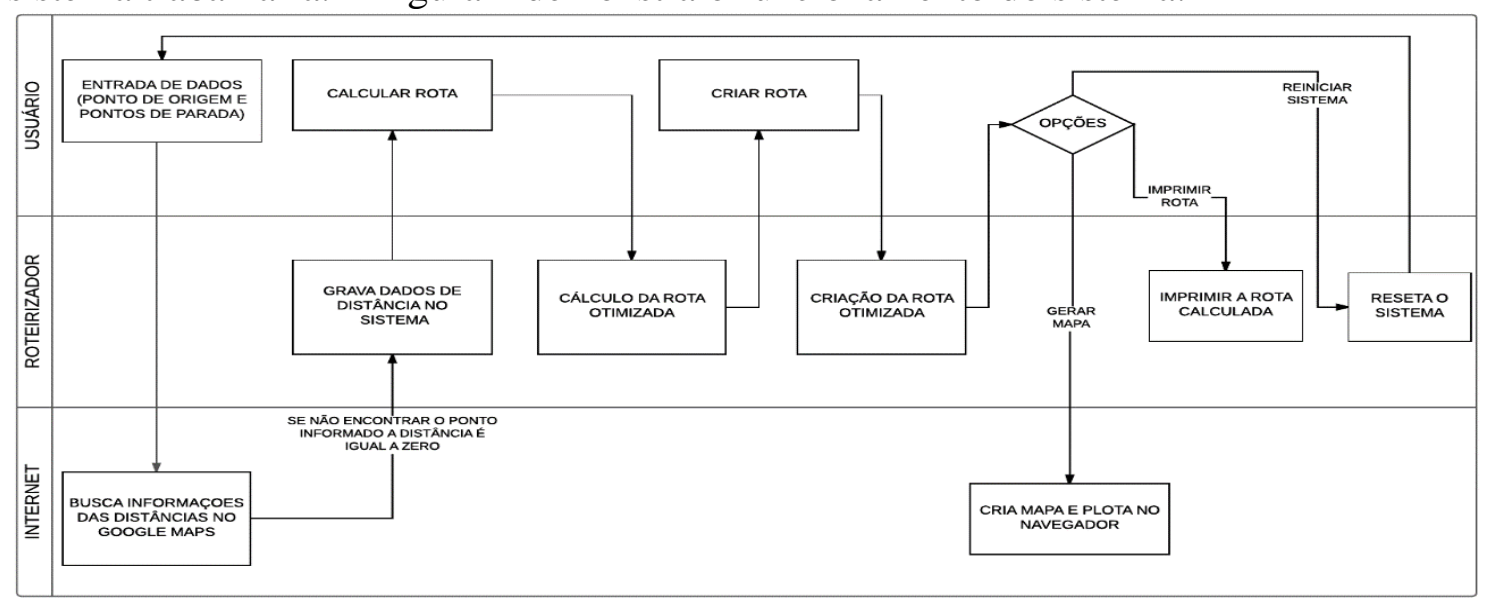

Figura 1: Fluxograma exemplificando o funcionamento do aplicativo

O sistema dispõe de duas telas funcionais sendo a primeira, a tela principal, onde são informados todos os dados a respeito da rota que se deseja otimizar (figura 2) e a segunda tela onde podem ser previamente cadastrados endereços que são frequentemente utilizados. Por se tratar de um software de cunho educacional, também foram incluídos recursos de acessibilidade como aumento da tela, descrição da tela via áudio e alto contraste para que o máximo de pessoas possam utilizá-lo sem problemas. 


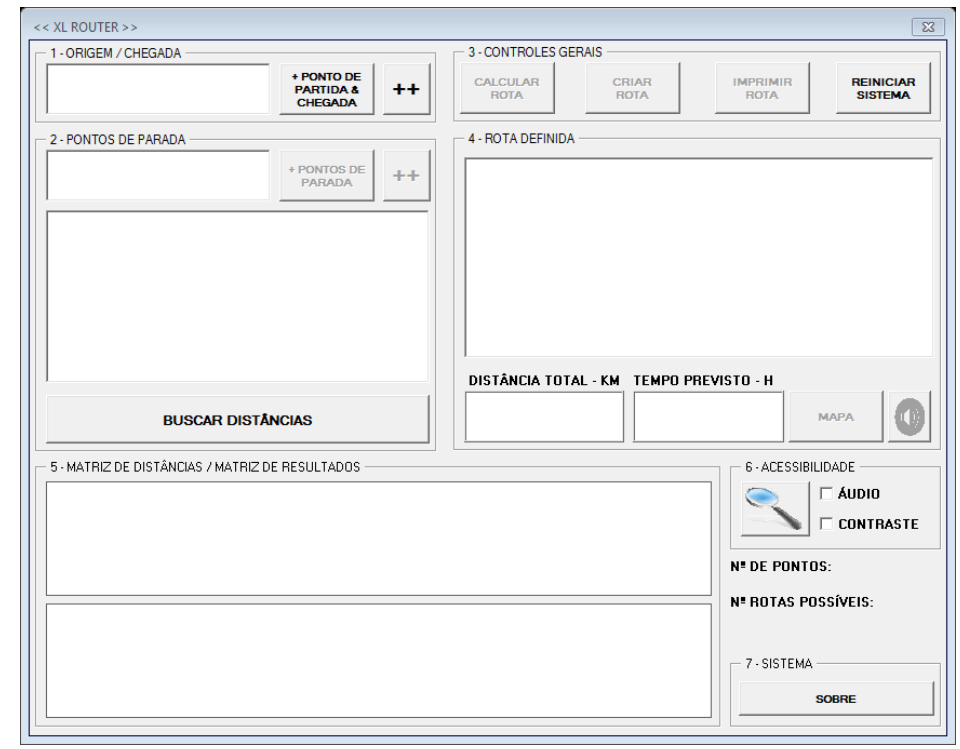

Figura 2: Tela Principal

Para adquirir os dados de distância entre os pontos de parada foi necessário programar o sistema para se conectar a base de dados do Google Maps. Houve também a necessidade de tratar os dados recebidos, para que o trajeto que fosse calculado refletisse o menor percurso possível. Foi necessário utilizar um sistema que não contasse com limitações de uso, fosse de livre utilização e que pudesse, assim como o solver nativo do Excel, ser programado via VBA. Neste quesito, o único que se adequou foi o OpenSolver. (OPENSOLVER, 2018). O trecho de código a seguir representa a chamada da rotina que define a função objetivo, as variáveis de decisão e cria as quatro restrições do PCV de acordo com os dados de pontos de parada e distância informados anteriormente.

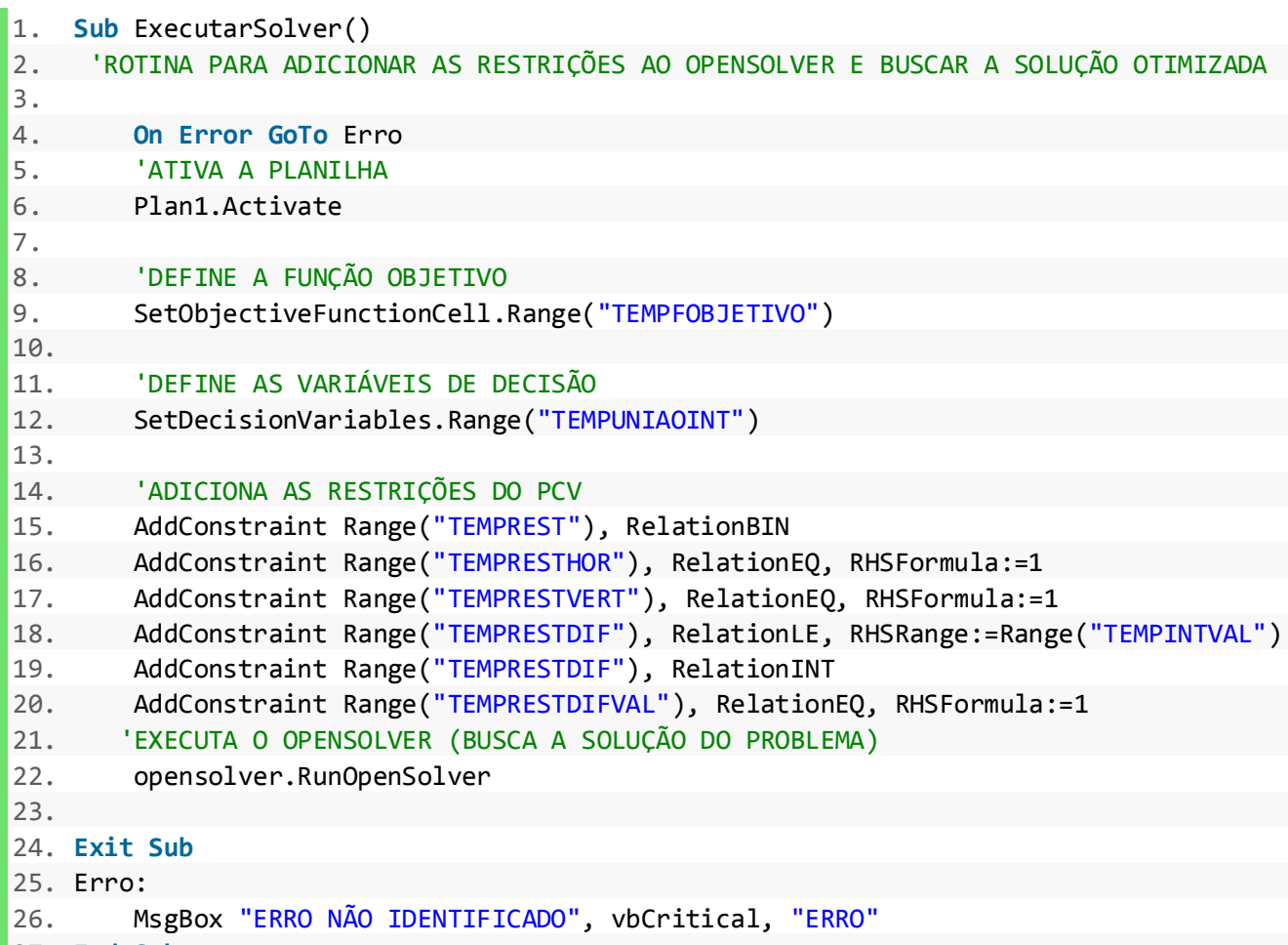


Vale salientar que o processo de coleta de dados de distância e tempo de viagem leva em consideração apenas distâncias rodoviárias e é informado em formato de quilômetros e horas, respectivamente.

\section{APLICAÇÃo PRÁTICA}

Durante o primeiro semestre do ano de 2018 no decorrer das aulas do curso técnico em logística no componente curricular denominado Gestão da Distribuição, os alunos foram desafiados em uma situação de aprendizagem complexa a informar dados otimizados a respeito de distância e tempo de viagem para se fazer uma série de coletas em diversos clientes. Apesar da simplicidade no processo de inserção de dados no sistema, a utilização correta estava condicionada a elaboração de uma atividade baseada nos conceitos da metodologia SENAI de educação profissional. Assim, foi proposto o problema descrito na tabela 1.

Tabela 1: Atividade prática

\begin{tabular}{|c|c|c|c|}
\hline \multicolumn{4}{|c|}{ PLANO DA SITUAÇÃO DE APRENDIZ } \\
\hline \multicolumn{4}{|c|}{ Curso: Técnico em Logística } \\
\hline \multicolumn{4}{|c|}{ Unidade Curricular: Gestão da Distribuição } \\
\hline \multicolumn{4}{|c|}{ ESTRATÉGIA DE APRENDIZAGEM } \\
\hline \begin{tabular}{l|l}
$\mathbf{x}$ & Situação-Problema \\
\end{tabular} & Estudo de Caso & & Pesquisa Aplicada \\
\hline \multicolumn{4}{|c|}{ Turno: Vespertino } \\
\hline \multicolumn{4}{|c|}{ DESCRIÇÃO DO DESAFIO } \\
\hline \multicolumn{4}{|c|}{$\begin{array}{l}\text { Dentre vários serviços que presta, a empresa MSD Logística oferta a seus clientes o serviço de } \\
\text { coleta de computadores defeituosos para que sejam levados a manutenção. Nos últimos meses } \\
\text { foi notado uma ampliação dos tempos de viagens e um aumento na quantidade de quilômetros } \\
\text { rodados pelos veículos que fazem estas coletas, com isso, o setor de planejamento de } \\
\text { distribuição analisou os endereços dos clientes e deduziu que é possível fazer a roteirização e } \\
\text { padronização das viagens para coleta dos computadores defeituosos. Utilizando as } \\
\text { ferramentas disponibilizadas, determine: } \\
\text { - O trajeto otimizado partindo da empresa MSD Logística; } \\
\text { - A quilometragem mínima de forma que atenda a todos os clientes; } \\
\text { - O Tempo estimado de viagem. }\end{array}$} \\
\hline \multicolumn{4}{|c|}{ DADOS DO PROBLEMA } \\
\hline \multicolumn{4}{|c|}{$\begin{array}{l}\text { Endereço da MSD Logística: Rodovia Darly Santos, Vila Velha - ES } \\
\text { Endereço Cliente A: Av. Dr. Olívio Lira, } 353 \text { - Praia da Costa, Vila Velha - ES } \\
\text { Endereço Cliente B: Av. Américo Buaiz, } 200 \text { - Ilha do Boi, Espírito Santo - ES } \\
\text { Endereço Cliente C: Av. Mario Gurgel, } 5353 \text { - São Francisco, Cariacica - ES } \\
\text { Endereço Cliente D: Av. José Maria Vivácqua Santos, 400, Vitória - ES } \\
\text { Endereço Cliente E: Av. João Palácio, } 300 \text { - Eurico Sales, Serra - ES }\end{array}$} \\
\hline \multicolumn{4}{|c|}{ RESULTADOS ESPERADOS } \\
\hline \multicolumn{4}{|c|}{$\begin{array}{l}\text { A partir dos recursos, informações e ferramentas disponíveis, o grupo deverá elaborar e } \\
\text { apresentar um relatório contendo a ordem de visitas aos clientes, a quilometragem prevista } \\
\text { para visitar todos os clientes e o tempo previsto de viagem. }\end{array}$} \\
\hline \multicolumn{4}{|c|}{ RELAÇÃO DE EQUIPAMENTOS NECESSÁRIOS PARA A PRÁTICA } \\
\hline & & & \\
\hline
\end{tabular}

Fonte: Autoria própria (2018) 
Utilizando os recursos disponibilizados, os alunos formaram grupos de trabalho e utilizando o software, conseguiram desenvolver a atividade de maneira rápida e precisa. No primeiro momento os alunos fizeram a inserção dos dados referente ao endereço do ponto de partida e dos clientes. Em seguida, solicitaram ao sistema a busca das distâncias e o cálculo que define o trajeto otimizado. Em alguns casos, por terem inserido informações de maneira incorreta, os resultados obtidos das distâncias não refletiam a realidade. Após os devidos ajustes, e os cálculos serem executados, o processo foi finalizado com a interpretação dos resultados gerado pelo sistema.

Dada a proximidade que estes alunos têm com equipamentos como computador, internet e aplicativos em geral, foi possível notar certa facilidade deles em absorver o conteúdo e conceitos propostos, chegando ao resultado esperado em pouco tempo. A tabela 2 informa o resultado esperado do exercício proposto.

Tabela 2: Resultados esperados

\begin{tabular}{llc}
\hline \multicolumn{1}{c}{ TRAJETO } & TEMPO & DISTÂNCIA \\
\hline Partida: MSD Logística & & \\
Parada 1: Cliente A & & \\
Parada 2: Cliente B & $01 \mathrm{~h}: 40 \mathrm{~m}$ & $64,7 \mathrm{Km}$ \\
Parada 3: Cliente D & & \\
Parada 4: Cliente E & & \\
Parada 5: Cliente C & & \\
Chegada: MSD Logística & \\
\hline
\end{tabular}

Fonte: Autoria própria (2018)

\section{CONSIDERAÇÕES FINAIS}

A utilização de situações de aprendizagem para a formação profissional é uma das bases da metodologia SENAI de educação profissional, todavia, a qualidade de sua aplicação pode ser comprometida caso os instrutores não disponham de uma ferramenta adequada para a prática. Sabendo desta necessidade e dos custos associados a aquisição de softwares que atenderiam este processo, este sistema de roteirização foi desenvolvido. Assim, este estudo esclareceu o processo de desenvolvimento de um sistema de roteirização desenvolvido em ambiente VBA que busca informar o menor trajeto entre um ponto de partida e $\mathrm{N}$ pontos de parada, bem como outros dados do trajeto como a relação entre partidas e paradas e o tempo previsto para viagem, de forma que possa ser utilizado em atividades práticas em um ambiente pedagógico.

Sendo $\mathrm{N}$ a quantidade de pontos no trajeto e substituindo este valor na fórmula $(N-1)$ !, é possível determinar a quantidade de trajetos possíveis entre ponto de partida e pontos de parada. Nesta situação de aprendizagem, seriam possíveis até 120 combinações diferentes o que de certa forma inviabilizaria o processo de roteirização de maneira manual. Utilizando o sistema proposto, este tempo foi reduzido consideravelmente já que os cálculos e combinações complexas foram feitas pelo próprio sistema.

Como foi dito, o emprego de simuladores para auxílio ao processo de ensino traz resultados positivos em diversas áreas. Todos os estudos de utilização de simuladores no processo de ensino e aprendizagem citados no referencial teórico deste artigo afirmam que há de fato um ganho de rapidez na absorção do conhecimento pelo aluno, 
já que as aulas se tornam mais atrativas, dinâmicas e estimulantes independente da área de aplicação.

Assim como nos estudos citados, ao associar a utilização de um simulador à prática guiada pela Metodologia SENAI de Educação Profissional foi permitido aos alunos otimizar o tempo de aprendizagem de uma etapa do componente curricular e tornar a aula mais envolvente e rica. De maneira geral, pode-se afirmar que as representações gráficas fornecidas pelo aplicativo possibilitam ao aluno absorver o conteúdo aplicado de maneira integral.

Vale informar que ao comparar os resultados obtidos com outras combinações possíveis de trajeto, houve uma redução de no mínimo 5 quilômetros e 10 minutos em cada viagem, como por exemplo, caso a ordem de visita dos clientes seja MSD > Cliente A > $\mathrm{B}>\mathrm{C}>\mathrm{E}>\mathrm{D}>\mathrm{MSD}$. Assim sendo, pode-se concluir que o desenvolvimento do software explicado neste artigo se tornou válido, já que seu objetivo de contribuir para o processo de ensino e aprendizagem foi alcançado em sua totalidade, além de dar rapidez e confiabilidade ao processo de definir trajetos otimizados e estar alinhado ao objetivo da Metodologia SENAI de Educação Profissional.

\section{REFERÊNCIAS BIBLIOGRÁFICAS}

ARENALES, M. et al. Pesquisa operacional para cursos de engenharia. Rio de Janeiro: Elsevier, 2015.

BALLOU, R. H. Gerenciamento da cadeia de suprimentos. 5. ed. Porto Alegre: Bookman, 2006.

BARROS, P. R. M. et al. Um Simulador de Casos Clínicos Complexos no Processo de Aprendizagem em Saúde. Novas Tecnologias na Educação, Junho 2012. Disponivel em: <http://seer.ufrgs.br/index.php/renote/article/view/30867/19223>. Acesso em: Abril 2018.

BATEMAN, R. E. et al. Simulação de Sistemas: Aprimorando Processos de Logística, Serviços e Manufatura. Tradução de Alain de Norman et d' Audenhove. Rio de Janeiro: Elsevier, 2013.

BELFIORE, P.; FÁVERO, L. P. Pesquisa operacional para cursos de administração, contabilidade e economia. Rio de Janeiro: Elsevier, 2012.

DA SILVA, E. M. et al. Pesquisa Operacional: Programação Linear. 3. ed. São Paulo: Atlas, 1998.

DREUX, M. D. A.; AZEVEDO, F. U. B. Macros para excel na prática. Rio de Janeiro: Elsevier, 2009.

FERRETI, C. J. et al. Novas tecnologias, trabalho e educação: um debate multidisciplinar. Petrópolis, RJ: Vozes, 1994.

FRONTLINE SYSTEMS. Frontline Systems. Excel Solver, Optimization Software, Monte Carlo Simulation, Data Mining, 19 Março 2018. Disponivel em: <https://www.solver.com/>. 
HECKLER, V.; SARAIVA, M. D. F. O.; FILHO, K. D. S. O. Uso de simuladores, imagens e animações como ferramentas auxiliares no ensino/aprendizagem de óptica. Revista Brasileira de Ensino de Física, Junho 2007. 267-273. Disponivel em:

$<$ http://hdl.handle.net/10183/116979>.

MANFREDI, S. M. Educação Profissional no Brasil. São Paulo: Cortez, 2002.

MASON, A. J. OpenSolver - An Open Source Add-in to Solve Linear and Integer Progammes in Excel. Operations Research Proceedings 2011, p. 401-406, 2012. Disponivel em: $<$ http://opensolver.org>.

NOVAES, A. G. Logística e Gerenciamento da Cadeia de Distribuição. 3. ed. Rio de Janeiro: Elsevier, 2007.

OPENSOLVER. OpenSolver For Excel. The Open Source Optimization Solver For Excel, 19 Março 2018. Disponivel em: 〈https://opensolver.org/>.

ROVANI, F. F. M. et al. Objetos de Aprendizagem Para Ensino de Geografia: Interação e Animação Com Simuladores. Novas Tecnologias na Educação, Julho 2012. Disponivel em: <http://seer.ufrgs.br/index.php/renote/article/view/30885/19238>. Acesso em: Abril 2018.

SANTOS, W. D. Uso de Simuladores Como Ferramenta no Ensino e Aprendizagem de Redes de Computadores em Um Novo Modelo de Ensino. Fundação Mineira de Educação e Cultura. Belo Horizonte. 2016.

SENAI, S. N. D. A. I. De homens e máquinas: Roberto Mange e a formação profissional. São Paulo: SENAI-SP, 2012.

SENAI, S. N. D. A. I. Série Metódica Ocupacional: O ensino profissional para o aprender fazendo. São Paulo: SENAI-SP, 2012.

SENAI, S. N. D. A. I. Metodologia SENAI de Educação Profissional. Brasília: SENAI/DN, 2013.

SENAI, S. N. D. A. I. Panorama mundial da educação profissional: desafios e respostas. Brasília: SENAI, 2015.

SENNA, P. et al. Ferramenta Desenvolvida em Visual Basic For Applications (VBA) Para o Ensino de Algorítmos de Caminho Mínimo. Simpósio Brasileiro de Pesquisa Operacional. Porto de Galinhas: [s.n.]. 2015. 